\title{
Modeling of steel and precast concrete components based on BIM systems and their application for the teaching of Architectural Design
}

\author{
Guilherme Quinilato Baldessin \\ University of Sao Paulo | Brazil | guilherme.baldessin@usp.br \\ Matheus Motta Vaz \\ University of Sao Paulo | Brazil | matheus.motta.vaz@usp.br \\ Givaldo Luiz Medeiros \\ University of Sao Paulo | Brazil | givaldo@sc.usp.br \\ Márcio Minto Fabricio \\ University of Sao Paulo | Brazil | marcio@sc.usp.br
}

\begin{abstract}
This paper addresses the development of parametric components based on BIM (Building Information Modeling) tools and their application for the teaching of architecture and urban designs, in a discipline focused on housing typology. As a didactic and research method, the use of industrialized building technologies in steel and precast concrete for production efficiency and low maintenance is associated with the idea of the studio as a laboratory for verification and experimentation. The system was improved for two years, and provided students with greater constructive control, basic feedback on the budget, and mastery of representation, while they investigated alternative design concepts and new components.
\end{abstract}

Keywords: Architectural Design; Building Technology; BIM; Higher Education; Housing.

\section{INTRODUCTION}

The progression of technology has led to a deep transformation in many aspects and fields, including Architecture, mainly regarding the design process, which has undergone one of the major changes over time.

The inception of computers into the architectural design process dates from 1960, according to Natividade (2010). After it "[...] had been developed in initially computational graphic systems, digital tools have been slowly incorporated in the architecture design practice, which has progressively expanded the number of possibilities and means of dialogue with other technological mechanisms" (Authors' translation, Natividade, 2010, p. 24).

Thereafter, the architectural design process has become increasingly digital, and the prospect is it will be more intensified.

In such a transformation process, the advances of BIM (Building Information Modelling) as a powerful design methodology are notable. This methodology has been adopted by both construction offices and the public sector - the latter will require the use of BIM in Brazil from 2021. According to Leal (2019), the Brazilian Building Industry is under a transition phase, i.e., moving from the traditional pattern and initial steps in terms of digital design,

${ }^{1}$ This research was applied in the Architectural Design II-A (Projeto II-A) discipline, which is part of the curriculum of Architecture and Urban Planning at the Universidade de dominated by the use of CAD (Computer-Aided Design), to the progressive implementation of the BIM process, a more advanced and interdisciplinary one. Therefore, academia must apply updated methodologies for classes.

Many countries have implemented BIM as a main tool in the building industry. In the United Kingdom, for example, it has been the first truly global technology in terms of digital building since 2012, and such a model will be soon implemented worldwide, as claimed by Arayci et al (2017).

Towards providing future professionals and staff with the necessary knowledge for handling this new reality, architecture schools have been testing different types of BIM applications. The importance of this change is reported by Delatorre (2015):

[...] students have pointed out the teaching of BIM inserted in the curriculum of architecture as an important part of their learning and that this practice should be continued. Some of them have highlighted most labor markets still do not use tools such as BIM, which hampers its insertion in internships. This may be one of the challenges for its adoption for teaching, which aims to prepare professionals to work with this new process that requires integrated and

São Paulo, and had the collaboration of student Gabriela Albano (in the first year) and professor Luis Espallargas Gimenez. 
collaborative practices, thus modifying the current scene. (Authors' translation, Delatorre; Pereira; Miotto, 2015, p.3)

All such efforts for the implementation of BIM have exposed the potential inherent to various aspects of the design process, especially regarding the impact on multidisciplinary work. This transformation was addressed by Batistello (2018), who demonstrated in the traditional architectural design, professionals work in the stages of analysis, synthesis, and evaluation separately, and their integration occurs further, thus probably leading to issues on adequacy and integration of parts and fields. On the other hand, BIM enables all specialties to operate simultaneously in a shared space, facilitating and speeding the identification of a problem.

Another issue regards the rationalization and industrialization of construction systems, which, in Brazil, started in the late 1950s. Until then, only a few cases of prefabricated buildings had been reported. An important example of such buildings is the Gávea racecourse (Rio de Janeiro, 1926), the first large-scale project that used concrete prefabrication in several construction elements, according to Vasconcellos (2002). In the 1960s, a seminal design focused on prefabrication, although mostly built traditionally, is carried out in "Zezinho Magalhães Prado" Housing Complex (1967) by Vilanova Artigas, Fábio Penteado, and Paulo Mendes da Rocha, with the collaboration of CECAP's architects (Caixa Estadual de Casas para o Povo), while "Conjunto Residencial da USP", in 1961, was a pioneering experiment of industrialization in a multi-storey complex undertaken by Eduardo Knesse de Mello, Joel Ramalho Jr., and Sidney de Oliveira. In the late 1980s, the use of prefabricated slabs and components in housing became more frequent.

Currently, various national sectors have discussed and developed building industrialization. Regarding the discipline in which this research was applied, the discussions also have an experimental and pedagogical character. First of all, it is taught in the third semester of the course, whose main subject is related to a housing project and its production, and introduces issues of rationalization of materials and modular design, based on prefabricated concrete or steel systems. The application of BIM in an introductory stage of the architectural design learning process highlights the links between formal and technical decisions, as a foundation for disseminating sustainable constructive knowledge. Throughout BIM modeling, students experience a process similar to the logic of the construction of a building, and permanently receive feedback on the implications of their design decisions.

In Brazil, the quality of the architectural design is not a priority in public housing policies. Some governmental programs such as those commissioned by the "Companhia de Desenvolvimento Habitacional e Urbano" (Housing and Urban Development Company) in São Paulo and the federal "Minha Casa, Minha Vida" ('My House, My Life') contribute to reducing the national housing deficit for lowincome people. However, they are oriented toward a quantitative aspect, whereas the qualitative one is not addressed with a similar commitment, differently from what is observed in the educational field. CEUs (Centros Educacionais Unificados - Unified Educational Centres, in São Paulo/SP) and FDE schools (Fundação para o Desenvolvimento da Educação - Foundation for the Development of Education) have developed high-quality notable architectural projects, due to their efforts for providing technical catalogs, including parametric components, models, and manuals associated with a design methodology focused on prefabricated systems in concrete or steel. Such strategies offer advantages for production and maintenance, hence, more efficient buildings, and ensure more accurate budgets.

Gabriela Albano, one of the collaborators of this research, conducted an initial study based on an analysis of several catalogs and projects of FDE schools, towards enhancing the vocabulary on precast concrete components and more deeply understanding the design of parametric components. Some companies specialized in precast concrete in Brazil, such as Usicon, Cassol, and Sudeste, also had their catalogs consulted in the survey. The applicability of all the components with the use of models provided by the Contier Architecture office was intensively studied for further reference for the composition and modification of parameters. After this initial stage in 2017, Albano started to develop the parametric Revit families of precast concrete that were applied to this research during its first year.

A remarkable aspect of the working process of BIM in architectural design is the approximation between digital workflow and real construction. Building management is addressed in several procedures in the BIM layers, such as quantitative tables, construction time, site organization, among others. Furthermore, the methodology requires higher accuracy in the building details, hence, a more specific commitment of architects and engineers with both design progression and steps for avoiding problems.

\section{METHODOLOGY}

An important aspect of this research is the classroom was assumed as a laboratory for testing the limits and potentials of the research, whose scope was revised and expanded. Accordingly, one of the objectives was to introduce the main functions and possibilities of the BIM from the start of the modeling process, which determined the choice of a reasonable LOD (Level of Development) for didactic purposes. According to the initial learning stage of the students, the adoption of LOD 300 (based on the standards available on the international platform BIM Forum) would be considered a good strategy as the goal for their final model, since this level involves sufficient data on both geometry and building details. The models would be accurately represented and the construction systems could be visualized.

The model templates also include tables containing the number and volume of beams and columns and occupancy rates. Values were inserted in a custom table to be consulted by the students throughout the design process, thus enabling the extraction of information from the model. Students could consult expenses, and, therefore, had a virtual balance between data and quality of their project. They were also provided with an extra layer of data and an extra parameter to be considered in the design of the buildings.

\section{DEVELOPMENT OF COMPONENTS}

This step, conducted during two years, involved the development and improvement of the digital parametric components according to BIM methodology, as well as discussions about the housing projects and use of steel or precast concrete in their main structure. 
Subjects on constructive details and dimensions of possible components were firstly analyzed towards a deeper understanding and supply of a good learning process and further professional practice. The specificities of prefabricated components with the desired materials, i.e., precast concrete and steel, were, therefore, checked.

During the first year of implementation, some precast components of AUTODESK REVIT software were studied. They had been previously prepared and were freely available on the Internet, such as the ones made by the FDE and the Contier Architecture Office. Such components enabled investigations on possible modifications and workability in their functionalities and parameters towards the generation of new parameters and/or components to be more intuitively modified, since mainly students in initial studies would use them.

Some national building agencies (e.g., CBCA - Centro Brasileiro da Construção em Aço - regarding steel; IBRACON - Instituto Brasileiro de Concreto - regarding concrete) were consulted for a more applicable reference. Structural components were then designed and modeled according to those references. The option for previously prepared components was chosen mainly due to the lack of theoretical material on the subject during the initial stage of the research.

After the first year, an assessment of the generated components revealed their both quality and quantity could be improved by rethinking and remodeling the parameters and the components themselves. The experience of the classes returned as a source for this new step.

In the second year and due to a deeper knowledge of BIM parametric modeling, new components were developed and the old ones were more accurately and intuitively remodeled. Therefore, the creation of new adjustments and parameters was enhanced, in comparison with those designed in the previous step.

Together with the components' library, a simple and generic model of their possible uses was built and made available for the students to check out some details (e. g., joints).

At the end of the research, it was verified whether the number of components available in the library had provided satisfactory workability for students. The assessment of the qualities of the components also revealed a positive impact on the classes.

\section{MONITORING CLASSES}

Towards presenting the building system to the students and solving possible questions concerning BIM methodology, parametric components, and modeling issues, the researchers helped the students with monitoring in the classes. This process was collaborative since the students gave feedback on the components, which also enabled evaluations of the efficiency of both components and parameters.

The monitoring classes were conceived in the following two aspects and steps:

- Explanation of the use and application of each component with its inherent integration and joints - a basic model was built in both constructive systems (precast steel and concrete) as an example for the students.

- Monitoring of the process - after the explanation, the proposed object of the discipline was presented (industrialized housing projects). While professors were helping the students to develop their architectural design, the researchers were acting as the software and the components' monitors, helping the students to solve their problems.

At the end of the first year, the monitoring was one of the main criteria for the continuation of the components' development, since, according to the students' feedback, some parameters could be improved and a larger library of components could be elaborated for expanding the range of applications regarding the purposes of the discipline.

Throughout the second year, the feedback revealed a more positive impact. The students related the components, parameters, and models had been correctly developed so that the expected tools for the designs were provided.

\section{STUDENTS' FEEDBACK}

By the end of each year of research, a questionnaire on the software, parametric components, and their application was applied to the students for checking the efficiency of BIM systems and monitored classes.

Remarkably, although the classes had been planned in different ways between 2018 and 2019, both forms showed similar questions, because the approach of the components was very similar. However, the students' answers were quite distinct.

\section{ANALYSIS OF STUDENTS' WORKS}

Finally, towards balancing the effectiveness of BIM more quantitatively, the following two assessments of the delivered works were conducted at the end of the second year and step of the research:

- Economy assessment, regarding the relationship among the number of housing units, their space and number of components; and

- Components and software use, regarding the correct use of components and software, required for the discipline presentation.

\section{ELABORATION OF TUTORIALS FOR STUDENTS' CLASSES}

Some tutorials were prepared for assuring new students would learn to use both the BIM component system and software resources with no academic monitoring. Data necessary for the components' correct work were supplied.

A handout and some online tutorials were elaborated. The handout presented the components, the way they are applied in the project, and how their parameters work, whereas the tutorials provided some tips and explanations hard to be addressed in the handout (e.g., functions of the software and integration of different components). 

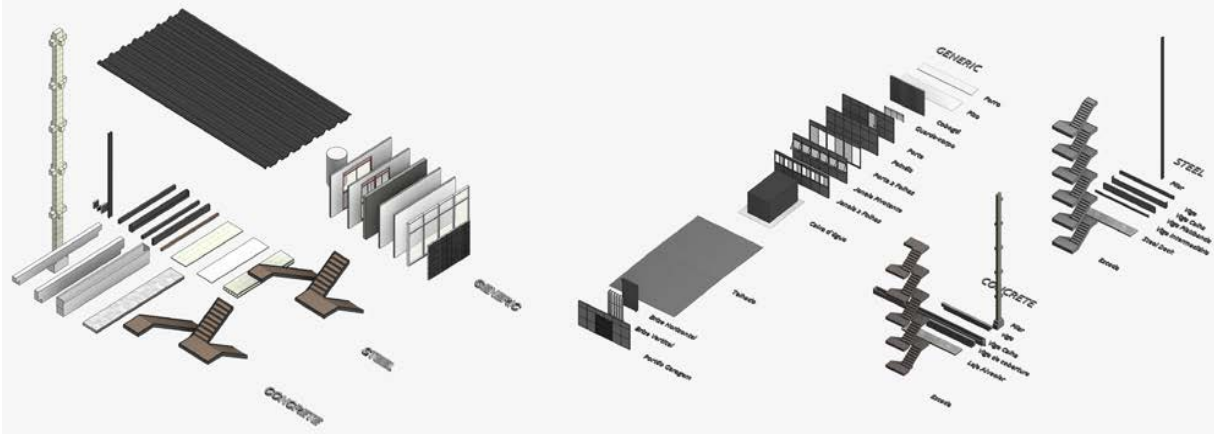

Figure 1: Components developed in the 1st year (left) and in the 2nd year (right) of the research.

\section{RESULTS}

Different components and materials were elaborated on and can be consulted by future students of the discipline. The presentation of results follows the steps of their production, and all topics were addressed twice (once per year), therefore, their comparison is more clearly seen through parametric components, generic models, and especially a variety of works developed by students in each year.

\section{PARAMETRIC SYSTEM AND COMPONENTS}

The components were developed in both steel and concrete systems so that the students could have an equivalent result for exploring similar possibilities in the project process, regardless of the systems' limits and potentialities

The library consists mainly of structural materials, such as beams, columns, and slabs, and common elements to be used with both systems (e.g. closures, windows, and roofs (Figure 1)) Although the students were encouraged to bring new components for assembling their projects, all modeled elements had some parameters and variabilities that guaranteed adaptations to different architectural designs. In the second phase, most components were remodeled, both quantity and accuracy of their parameters were increased, and a wider range of variability and a higher adaptability level were provided.
Finally, in both years, simple demo models were built with all components for showing the way the components and the joints work together in practice (Figure 2). Such generic BIM models were proposed as a modular construction without a fixed function, and developed in both materials and construction systems of steel and concrete, for illustrating their inherent applications.

\section{STUDENTS' WORKS}

As a result of the application of the parametric component system, a range of architectural designs was developed by the students, showing the variability in such a system. The designs involved houses, apartment blocks of different heights, typologies of single or duplex units, access by vertical stairs or horizontal galleries, terraces and balconies, alternative use at ground level, and a diverse articulation with the proposed surroundings. Some housing facades are more colorful, whereas others are neutral, forming a radiant or sober urban complex. Each design developed by the groups resulted in a singular building, thus demonstrating a large scale of possible approaches based on the same tools, same references, and same methodology (Figure 3).

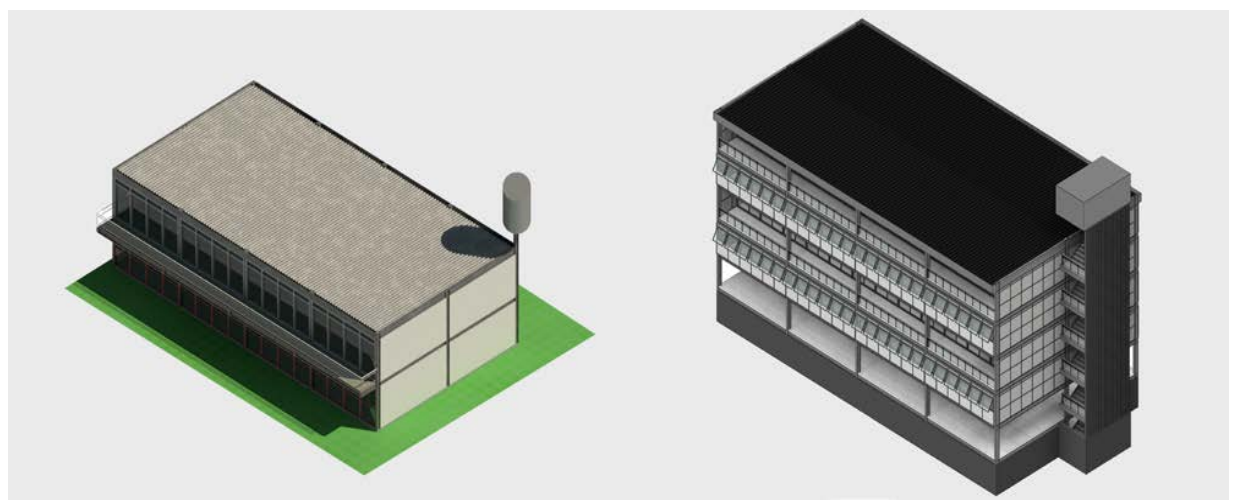

Figure 2: Example of a model designed with the steel construction system) in the $1^{\text {st }}$ year (left) and in the $2^{\text {nd }}$ year (right) of the research. 

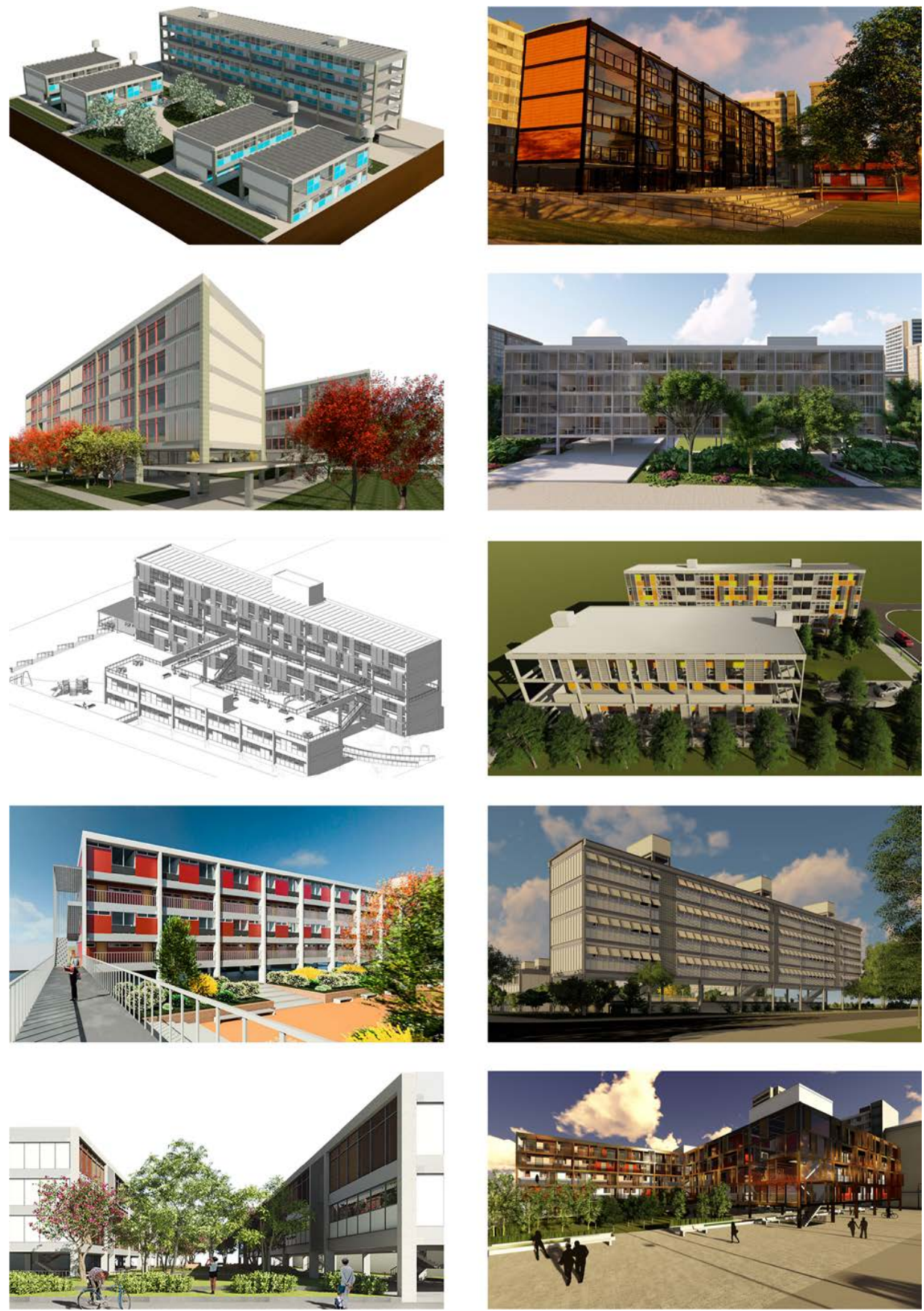

Figure 3: On the left, examples of the 2018 student's production; on the right, examples of the 2019 production. The housing complexes were designed by the students indicated below. All images belong to the authors of the respective housing complex. Both authorships are indicated from top to bottom, starting from the left column. Figure 3.1: Júlia Gonçalves, Lídia Sogawa, Marina de Padua, and Mateus Vasconcellos. Figure 3.2: Julia Elias, Maria Alice Messias, Maria Sylvia Serra, and Millena de Morais. Figure 3.3: Bianca Vieira, Cynthia Diniz, Mayara Fook, and Vagner Oliveira. Figure 3.4: Diego Zumpano, Gabriel Garcia, Isabela Okada, and Rodrigo Oliveira. Figure 3.5: Gabriel Dierings, João Victor Mariotti, Mateus Barufi, and Mayara Sentalin. Figure 3.6: Carolina Silva, Fabiana Palmeira, Júlia Simabukuro, Marcela de Oliveira, and Márcio Lino. Figure 3.7: João Gabriel Rosa, Lara Rossi, Mayara Macedo, and Yasmin Migliati. Figure 3.8: Brenda Ballastreire, Heitor Tessarolli, Juliana Martins, and Lara Brisante. Figure 3.9: Fernanda Norato, Ingridth Hopp, João Batista Stivanin, and Leticia Aquareli. Figure 3.10: Andressa Nora, Jacqueline Rugai, Júlia Medici and, Marina Dantas 


\section{ANALYTICAL CRITERIA}

The students' works developed in the last year of the research (2019) are highlighted in this paper to be compared in terms of consistency of components and software, and economy, for analysis of reasonability of their application and understanding. A range of values from 0 to 5 was defined for the evaluation of their application regarding the following topics: (Table 1):

- Use: correct use of components in terms of size, joints, and spacing, determined by the chosen construction system, in which a larger number of issues means a lower mark;

- Extra: use of components not included in the original system for the composition - the templates provided enough components for the main aspects of the buildings, nevertheless, students required some extra components to complete their projects in the exercises:

- Organization: use of the software and the methodology established for the proposed building system in the BIM environment;

- Innovation: an extra point (range 0-1) was scored to the groups that applied the proposed components in a creative and different, but correct way; and

- $\quad$ Average: calculated among the three initial topics (use, extra, and organization) plus the possible extra point in innovation.

Table 1: Marks related to the uses of components and software by the students. ${ }^{2}$

\begin{tabular}{|cccccc|}
\hline Group & Use & Extra & $\begin{array}{c}\text { Organi } \\
\text { zation }\end{array}$ & Innovation & $\begin{array}{c}\text { Avera } \\
\text { ge }\end{array}$ \\
\hline 1 & 1 & 5 & 4 & 1 & 3.67 \\
\hline 2 & 3 & 5 & 4 & 1 & 4.33 \\
3 & 3 & 5 & 3 & 1 & 4 \\
\hline 4 & 5 & 5 & 5 & 0 & 5 \\
\hline 5 & - & - & - & - & - \\
\hline 6 & 2 & 5 & 5 & 1 & 4.33 \\
\hline 7 & 4 & 5 & 4 & 1 & 4.67 \\
\hline 8 & 5 & 3 & 5 & 0 & 4.33 \\
\hline 9 & 5 & 5 & 5 & 1 & 5.33 \\
\hline 10 & 3 & 5 & 4 & 1 & 4.33 \\
\hline 11 & 2 & 4 & 3 & 1 & 3.33 \\
\hline Average & 3.3 & 4.7 & 4.2 & 0.8 & 4.33 \\
\hline
\end{tabular}

The second assessment offered a practical value in terms of material spent in the housing complex and the number of habitations created. Some works did not use the components and the construction system as proposed, consequently, the number of components in the table is not the real one. Moreover, the number of building typologies varied, and, therefore, a mathematical formula was elaborated for providing students with a fairer analytical criterion for evaluation:

\footnotetext{
${ }^{2}$ The file of Group 5 was corrupted, hampering a correct analysis of their work.
}

(number of columns $x$ number of floors $x 100$ ) / (number of habitations $x$ space of habitation $\left(\mathrm{m}^{2}\right)$ )

The following aspects of the formula must be observed:

- number of columns, which estimates the material spent in the length of the building, since the space between the columns was fixed in the proposed exercise); and

- $\quad$ the number of floors, which estimates the material spent in the height of the building.

The results were converted to the desired standard for the comparison of the economy of materials and the use of BIM components (according to table 1). The average of all marks was also included (Table 2):

\section{Table 2: Combination of marks of Economy and Use of Components.}

\begin{tabular}{cccc} 
Group & Economy & $\begin{array}{c}\text { Components } \\
\text { use }\end{array}$ & Final Mark \\
\hline 1 & 3 & 3.67 & 3.33 \\
2 & 4 & 4.33 & 4.17 \\
3 & 3 & 4 & 3.5 \\
4 & 4 & 5 & 4.5 \\
5 & - & - & - \\
6 & 2 & 4.33 & 3.17 \\
7 & 5 & 4.67 & 4.83 \\
8 & 5 & 4.33 & 4.67 \\
9 & 5 & 5.33 & 5.17 \\
10 & 5 & 4.33 & 4.67 \\
11 & 4 & 3.33 & 3.67 \\
Average & 4 & 4.33 & 4.17 \\
\hline
\end{tabular}

The marks provided a clearer view of the efficiency of the components. Since their average was high, the students' standard of the material economy and use of software and components were well-received.

\section{STUDENTS' FEEDBACK}

In both years, a questionnaire applied checked the necessity of continuing the development and improving the components. In the first year, the answers showed the library might have more components for maximizing the variations in the architectural compositions, and some issues were related to specific components. This was one of the main reasons for the continuation of the research.

On the other hand, after the second year, the answers were distinct, i.e., the students reported the components' library was enough and the functions and parameters of the components were adequate. In both years, some questions were given positive answers (e.g., those regarding the use of BIM as both methodology and software, approved to be employed by future students).

\section{ONLINE TUTORIALS AND HANDOUT}

The handout (Figure 4) showed the components' system and the way each parameter worked individually. Extra 

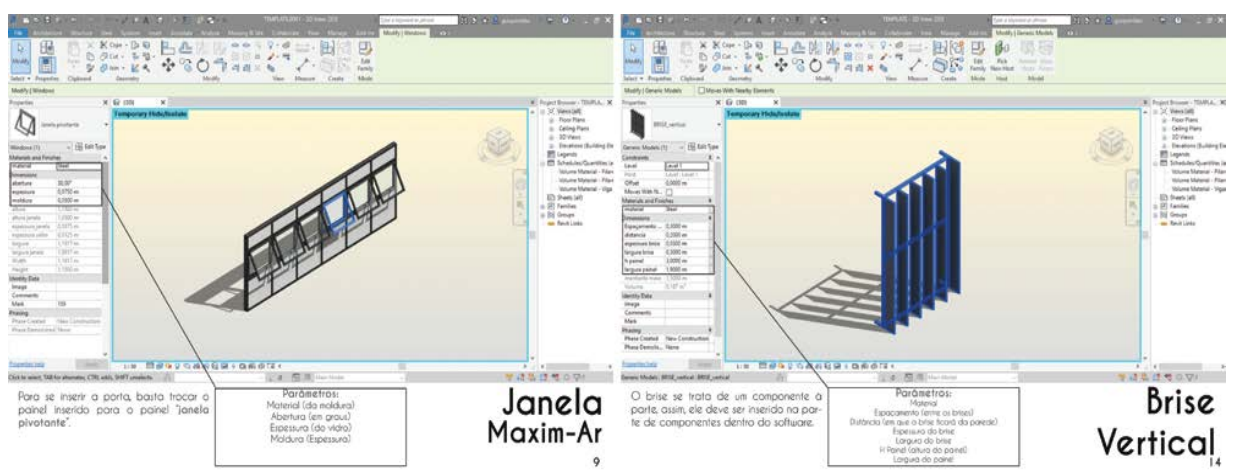

Figure 4: Pages of the handout for future students of the discipline.

information was included for some more complex components.

The final generic models were also provided for future students of the discipline as a basis for showing them how the joints of the components work in their entirety.

Some videos with tips on the software were posted on YouTube (Figure 5) and showed procedures such as the creation of quantitative tables and the way the concrete column (most complex component) works.

All such online tips are available to be consulted by the students and those interested at:

- https://www.youtube.com/watch?v=6IXxjWEXSs\&t=14s (for creation and consultation of tables):

- $\quad$ https://www.youtube.com/watch?v=E1faGVEesd c (for Revit tips); and

https://www.youtube.com/watch?v=LJe0aMac7II (for concrete column presentation).

\section{DISCUSSION}

The teaching of new approaches of BIM methodology and use of industrialized pre-cast components in housing projects in an undergraduate discipline requires new knowledge for increasing the quality and use of such terms in the national context, where some federal programs have implemented a typology of houses towards responding to the same issue, i.e., the housing deficit, however, with no architectural and urban quality, as explained by Medeiros in Enanparq (2018).

Because the discipline was in an introductory point of the graduation curriculum, the proposed exercise neither promoted much integration with other building areas nor underwent all stages of a real project. Although the students' engagement with BIM methodology was not deeply observed, the proposed system served as a tool for $3 \mathrm{D}$ modeling, as a quantifier of the materials and costs spent, and for technical drawing automation. In any case, the knowledge of more complex resources is addressed from the beginning of the course, towards broadening the understanding of the nexus between architectural form and construction techniques.

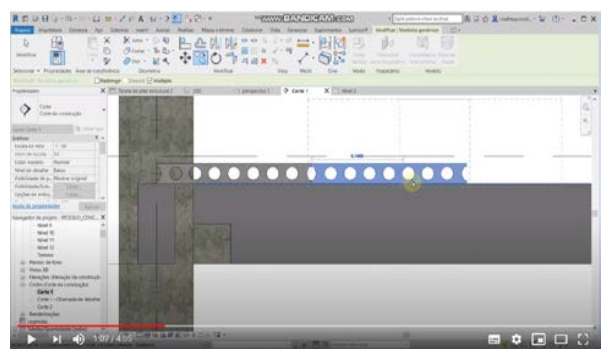

Figure 5: Example of the tutorial video developed at the end of the research for future students of the approached discipline.

A comparison of the works developed in 2018 and 2019 revealed an increase in the number of components, and that the solutions proposed by the students became more specific and distinct. In the article entitled "The four FDE schools of Campinas" and published in Tracés magazine, Espallargas (2005) analyzed four projects in Campinas, Brazil, with similar issues based on the FDE analogous catalog of precast concrete components. The terrain was virtually the same as those working in both years as a hypothetical site. A comparison of all students' works showed the quite different housing complexes clarified the variability and adaptability of the proposed parametric components and demonstrated the use of standardized elements does not necessarily result in similar architectural designs.

The study also highlighted the way the rationalization applied in the housing design process does not necessarily mean the establishment of a project pattern with the recurring use of ready-made solutions. The central issue in this sense is the integration of advanced prefabrication techniques with the design of each situation and investigation on alternatives for public housing policies that support the learning process without disregarding tectonic criteria, by articulating systemic and experimental approaches.

\section{CONCLUSIONS}

Requirements for future architects change, leading Architecture schools to be aware and reflect on the future 
of the profession and its new patterns of methodologies that are about to come.

Industrialization has progressively transformed Brazilian projects including elements such as pre-cast components of different geometries and materials, thus requiring reanalyses of the means used for the development of a project. In such a context, the inception of BIM is an action for redrawing the project process.

BIM is becoming a standard methodology in Brazil since public policies have started to implement it. However, such a methodology has increased in complexity and improved its tools, functions, and integration. The implementation of future technologies will constantly modify the Architecture profession, changing both its views and paradigms.

The exploration of novel approaches and the implementation of new demands are mandatory in the educational field, starting from an undergraduate process. This paper has introduced an approach that ponders and evaluates the application of a new methodology, such as $\mathrm{BIM}$, towards improving the teaching and learning process through a deeper knowledge of building systems and materials supported by their currently available tools.

\section{REFERENCES}

Arayci, Y., Counsell, J., Mahdjoubi, L., Nagy, G., Hawas S., Dewidar, K. (2017). Heritage Building Information Modelling. Taylor \& Francis Group. New York, NY. ISBN: 978-1-13864568-4

Batistello, P., Balzan, K. L., Pereira, A. T. C. (2019, April). PARC Pesquisa em Arquitetura e Construção. Campinas, SP, v. 10. ISSN 1980-6809.
BIM Forum (2018, September). Level of Development (LOD) Specification Part I and Commentary - For Building Information Modeling and Data. BIM Forum (2018 ed.) Retrieved from https://bimforum.org/resources/Documents/BIMForum_LOD_ 2018_reprint.pdf

Contier Architectural Office (2011). Famílias MCMV. São Paulo. Retrieved from http://contier.com.br/downloads

Delatorre, V., Pereira, A. T. C., Miotto, J. (2015). BIM: Relatos de aplicação no ensino de arquitetura. SIGRADI, 2015.

Espallargas G. L. (2005, August). Les quatre écoles de la FDE à Campinas. Lausanne, Tracés, 19-24. Vitruvius Arquitextos. ISSN 1809-6298. Retrieved from https://www.vitruvius.com.br/revistas/read/arquitextos/06.064/ $422 / \mathrm{fr}$

FDE (Fundação para o Desenvolvimento da Educação) (2019), Catálogos Técnicos. São Paulo, SP. Retrieved from https://produtostecnicos.fde.sp.gov.br/Pages/CatalogosTecni cos/Default.aspx

Leal, B. M. F. (2019). BIM no ensino de tecnologia da construção: Estudo de caso. PARC - Pesquisa em Arquitetura e Construção. Universidade Federal do Rio de Janeiro, Rio de Janeiro, RJ. ISSN 1980-6809.

Medeiros, G., Gimenez, L., Fabricio, M. (2018). Arquitetura, préfabricação e produção da cidade: uma experiência de ensino com a modelagem digital de componentes construtivos para projetos habitacionais.

Natividade, V. (2010). Fraturas Metodológicas nas Arquiteturas Digitais. Universidade de São Paulo, São Paulo.

Vasconcellos, C. S. (2002) Planejamento: projeto de ensinoaprendizagem e político-pedagógico. São Paulo: Libertad. 